\title{
A FERTILITY INDEX DERIVED FROM SEMEN ANALYSIS
}

\author{
BY \\ CLARE HARVEY \\ From the Department of Zoology, University College of the South West, Exeter
}

(RECEIVED FOR PUBLICATION APRIL 2, 1953)

The study of human semen and its importance in assessing the probable fertility of a given marriage has received a great deal of attention in recent years. Unlike blood or urea estimations, semen analysis has no fixed standards of normality. Harvey and Jackson (1945) and Hammen (1944) showed that the criteria of fertility given by earlier workers (Moench and Holt, 1931 ; Hotchkiss, 1936 ; Lane Roberts, Sharman, Walker, and Wiesner, 1939; Weisman, 1941) were set far too high. More recent work (Falk and Kaufman, 1950; MacLeod, 1951) has shown that excellence in one quality, such as motility, may compensate for poorness in another, such as density. The method used in this laboratory of giving $\mathrm{A}, \mathrm{B}$, or $\mathrm{C}$ for each semen character and describing the semen in terms of the number of "As" scored does imply compensation, and still proves a useful method of assessment. It has, however, several disadvantages. The categories denoted by each letter cover a wide range of values, and, as always in a discontinuous classification, the difference between A and B may be insignificant if both are borderline values. Neither is there any means of determining how much an A in one character may offset a B or C in another. Probably, however, the greatest disadvantage lies in the impossibility of using such a classification for mathematical processes, even one so simple as determining the mean values of a series of several specimens produced by the same donor.

The present work was undertaken with the object of combining the results of semen analysis in a single numerical expression which, in addition to being an estimate of the donor's fertility, could also be used for studying response to treatment, and for classifying semen for purposes of experimental research.

\section{The Basis of the Calculation}

A study was made of 150 couples who had sought advice because of sub-fertility between
December, 1947, and June, 1949, or had submitted semen for some other reason during this period All the couples had remained in touch with the clinic until either the wife became pregnant of until March, 1951, whichever was the earlier.

Density.-When the sperm density was plotte $\vec{d}$ against the percentage of conceptions the fertilit rate increased rapidly from 0 for the azoosperm semens to $35 \%$ for specimens with $20 \mathrm{~m}$. sperms per $\mathrm{ml}$. A further gradual increase occurred witt increasing sperm concentration up to $100 \mathrm{~m}$. pe्t ml., in which group the conception rate was $50 \%$ The distribution of the points above $20 \mathrm{~m}$. per m may equally well be interpreted as a random dis tribution, indicating no improvement in fertilit above this point. MacLeod (1951) and MacLeof and Gold (1951), using quite a different approact arrived at the same conclusion that a density of $20 \mathrm{~m}$. per $\mathrm{ml}$. gives the maximum chance of fers tility. In the present work improvement up tơ $100 \mathrm{~m}$. per $\mathrm{ml}$. is assumed, and for simplicity Fig. has been drawn by joining the point $(0,0)$ to $(70,20)$ and then joining $(70,20)$ to $(100,100)$ by straigl lines. The conception rates on the vertical ax: are expressed as percentages of the rate for the best group, the assumption being that there would be no infertility in this group if the wives were fully fertile.

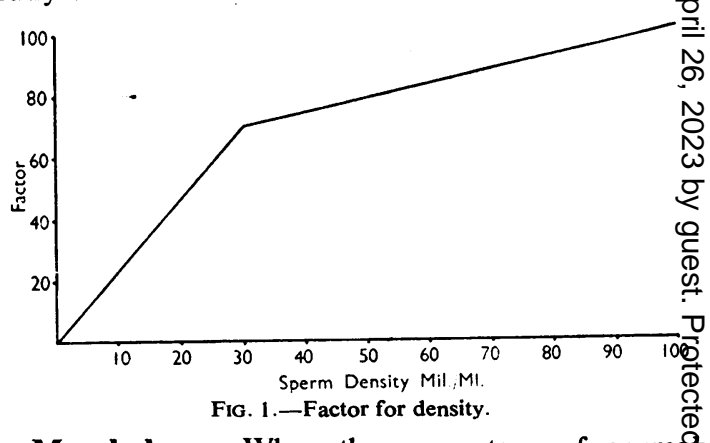

Morphology.-When the percentage of normal sperms in the semen was plotted against the 
success rate a steady improvement occurred from the group with less than $10 \%$ normal sperms up to that with $70 \%$ normal sperms. In the highest group the rate was again $50 \%$. This relationship is shown in Fig. 2.

Motility.-As semen comes to this laboratory from all over the county, the time between ejaculation and examination varies from one to five hours, and sometimes longer. In order to eliminate the differences in percentage motility due to the different ages of the specimens, the motility was expressed as the ratio of the observed

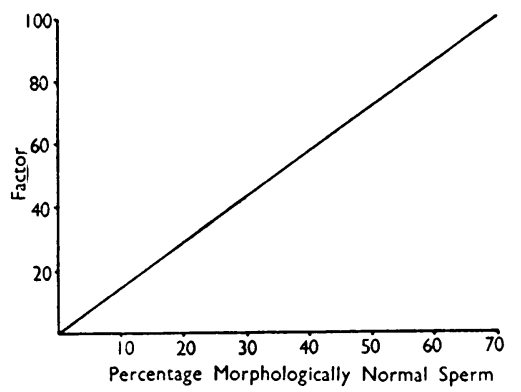

FIG. 2.-Factor for morphology.

percentage of progressing sperms to the minimum expected in an $A$ specimen at the same time after ejaculation. This figure is called the "motility ratio" and has been explained fully elsewhere (Stallworthy, Walker, Malleson, and Jackson, 1953). This ratio considered alone did not give the clear-cut relationship with fertility shown in Figs. 1 and 2. If, however, the specimens were arranged in series of the product of the conception rates expected from their density and morphology, as read off from the two graphs Fig. 1 and 2, and

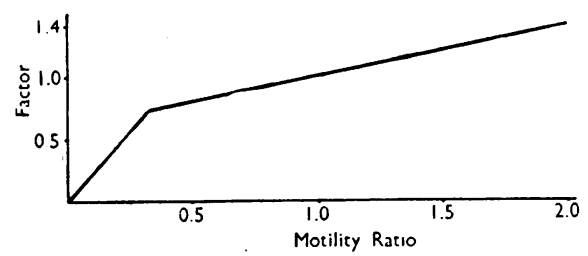

FIG. 3.-Factor for motility.

the series broken up into groups, within each group the motility ratio bore a close relation to the chance of success. This was best expressed as a factor modifying the product of the two other values. The relation between this factor and the motility ratio is shown in Fig. 3. In practice it is easier to tabulate the factors as shown in Table 1 .
TABLE I

FACTOR DERIVED FROM MOTILITY RATIO FOR CALCULATING FERTILITY INDEX

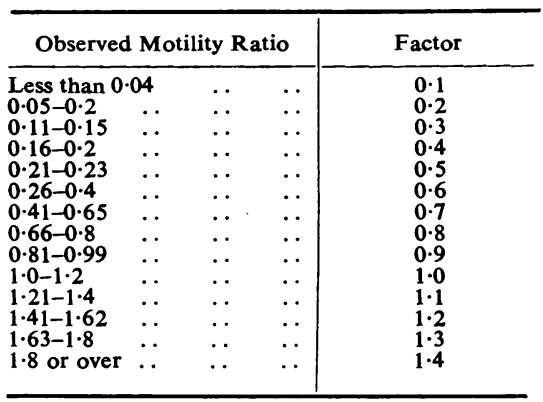

\section{The Calculation}

The sperm density, percentage of normal forms, and motility ratio are found by the ordinary routine of semen analysis. The theoretical conception rates and the factor for motility are obtained from the graphs and table. The three factors are multiplied together and the product divided by 100. This can be done with a slide rule in about 30 seconds. The answer is the fertility index. The method is illustrated in Table II. It will be seen

TABLE II

CALCULATION OF FERTILITY INDEX

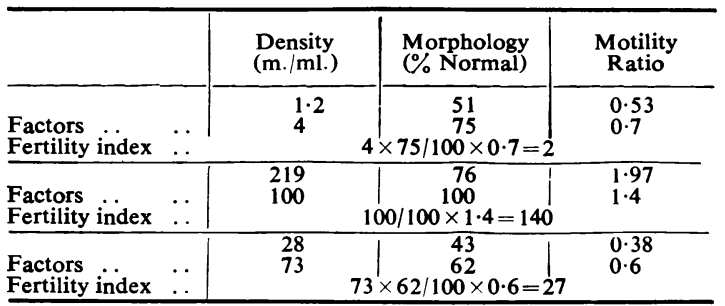

that the index may be greater than 100 , but there is no increase in the chance of success above this level.

\section{Application to Larger Groups}

The reliability of the index was first tested by applying it to 656 husbands of sub-fertile marriages. No cases were used if reliable information about conception or failure was not available for a period of 18 months after the wife's first visit to the clinic. Men with azoospermic semen were not included. The results of the first analysis were disappointing. While some gradation of conception rate with fertility index occurred, only the extreme groups were statistically significant. About 200 of the men in this series had sent two or more specimens, and the mean value of these gave a 
much better correlation with fertility than the best value of each donor. In the earlier years of the clinic it was not usual to ask for a second specimen if the first was satisfactory, and only 479 cases could be used for testing the significance of the mean fertility index as a measure of chance of conception. The relationship is shown in Fig. 4.

In interpreting this result, it must be remembered that it is based on sub-fertile marriages, and that the fertility of the wives is probably much lower in the case of men with high indices than in those where it is low. This accounts for the shape of the curve. Subdivision of the two lower points into groups with a fertility index of less than 1 , $1-9,10-19$, and 20-29 shows a very good fit over the steep part of the curve, although the numbers involved are too small to be statistically significant.

The greater significance of the mean value can be understood when it is remembered that the wife's fertile period lasts only a very short time each cycle. The chances of a good ejaculate being produced at this time are obviously greater where the husband's semen is uniformly good than where it varies in quality.

\section{Husbands of Fertile Marriages}

It is extremely difficult to get fertile men to submit semen for examination, and only 33 cases were available for comparison with the sub-fertile series. Table III gives a comparison of the distribution of fertility indices in the fertile group

TABLE III

FERTILITY INDICES OF HUSBANDS OF FERTILE MARRIAGES

\begin{tabular}{|c|c|c|c|c|}
\hline $\begin{array}{c}\text { Fertility } \\
\text { Index }\end{array}$ & & $\begin{array}{l}\text { Expected } \\
\text { No. from } \\
\text { Subfertile } \\
\text { Group }\end{array}$ & $\begin{array}{c}\text { Observed } \\
\text { No. }\end{array}$ & Significance \\
\hline $\begin{array}{l}90-100+ \\
70-89 \quad \ldots \\
50-69 \quad \ldots \\
30-49 \quad \ldots \\
20-39 \quad \therefore \\
\text { Under } 10\end{array}$ & $\begin{array}{l}\cdots \\
\cdots \\
\cdots \\
\cdots \\
\cdots\end{array}$ & $\begin{array}{l}4 \cdot 0 \\
4 \cdot 04 \\
6 \cdot 15 \\
7 \cdot 9 \\
6 \cdot 9 \\
4 \cdot 01\end{array}$ & $\begin{array}{r}17 \cdot 0 \\
7 \cdot 0 \\
5 \cdot 0 \\
4 \cdot 0 \\
- \\
-\end{array}$ & $\begin{array}{l}\text { Significant } \\
\text { Probably significant } \\
\text { Probably significant } \\
\text { Significant } \\
\text {," }\end{array}$ \\
\hline
\end{tabular}

compared with what would be expected in a similar number of cases drawn from the sub-fertile series. It will be seen that half the fertile group have fertility index above 90 . This suggests that for mixed population the slope of the curve would be much steeper in the upper part. Undoubtedly in a larger series some fertile men would be found wiकू fertility indices below 30 , but probably very few.

\section{Interpretation of the Fertility Index}

The conception rate corresponding to a give fertility index as derived from Fig. 4 gives the average chance of success for a sub-fertile coupla being investigated at a clinic over a period of $\mathbb{\&}$ months to two years. Several of the patients whoo are included as unsuccessful in this series haye since conceived. The actual chances in any speciffc case will depend on the fertility of the wife. $\Phi_{f}$ the wife is fully fertile the chances will be abott twice those shown by the graph.

It may be deduced from these results that if the husband's fertility index, based on two or moge semen examinations, is 70 or over the sub-fertility is due almost entirely to the wife. Where the index 
is below 30 the husband's sub-fertility alone may be enough to account for the wife's failure to conceive during the period in question.

\section{Application to Experimental Work}

The significance of the fertility index as a measure of semen quality, quite independent of its relation to chances of conception, has been demonstrated in a series of experiments on the penetration of cervical mucus by spermatozoa in vitro. Details of this work will be published elsewhere, but Fig. 5 illustrates the relation between the

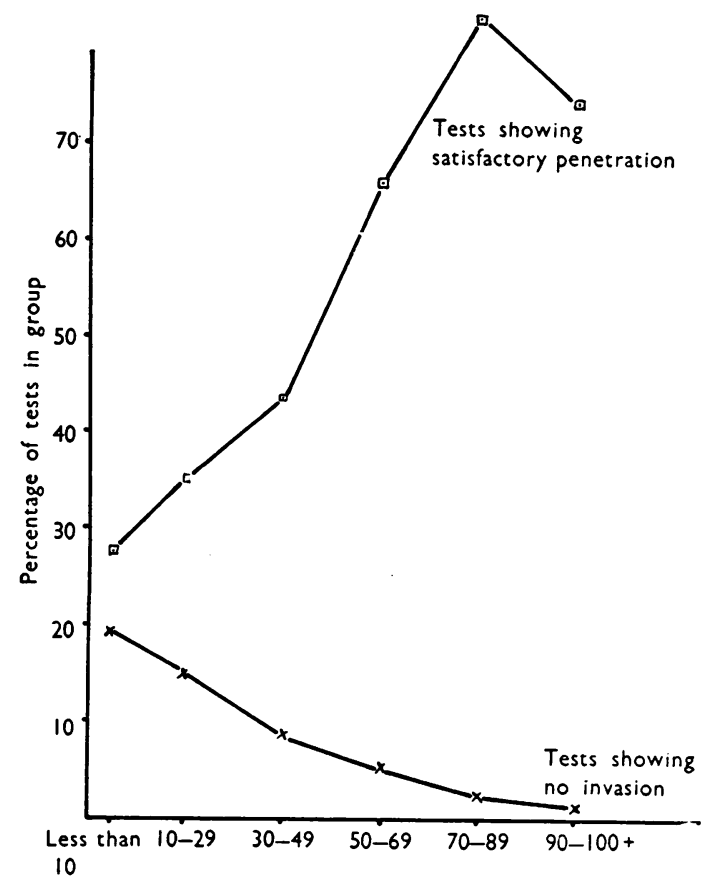
Fig. 5.-Fertility index of semen and penetration of cervical mucus
(in vitro).

fertility index and the number of mucus samples invaded, and the number showing satisfactory progress in the mucus. This relationship was closer than that shown between penetration and either sperm density or morphology considered alone.

The fertility index has also been used for classifying semen to demonstrate the relationship between semen quality and certain biochemical characteristics of the semen plasma (Harvey, 1951).

\section{Response to Treatment of Male Sub-fertility}

The principal clinical use of the fertility index is as a measure of improvement or deterioration in semen as a result of therapy. This involves some decision as to what may be regarded as a significant change in the value of the index. Where a series of five or more specimens have been examined for one patient, as in the case of artificial insemination, husband (A.I.H.) donors, the variance of the fertility index can be calculated by ordinary statistical methods. In most cases, however, not more than two specimens are examined before the husband is given treatment. If the indices of these two specimens differ from their mean by more than $20 \%$ of the mean value it is advisable to ask for a third specimen. Where the first two specimens are similar an improvement of the order of 10 to 20 above the mean pretreatment value is almost certainly significant. Where the mean pre-treatment value is below 10 an increase of 5 or more, if established by two subsequent tests, probably represents a real improvement, and at this level even a small increase gives a greater chance of conception. Where the semen is variable before treatment relatively large improvement is required before the treatment can be regarded as effective.

Table IV gives the history of a patient who responded well to treatment with intermittent methyl testosterone.

TABLE IV

EFFECT OF METHYL TESTOSTERONE THERAPY ON THE FERTILITY INDEX

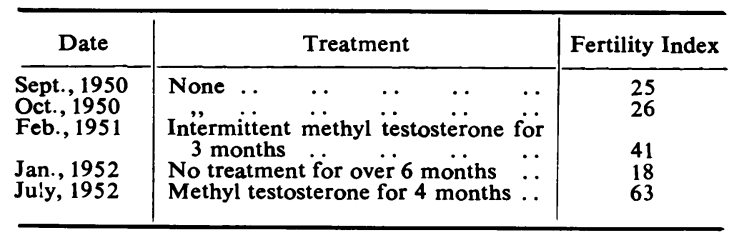

\section{Conclusion}

The observations quoted in this paper establish the fertility index as a genuine biological measure of semen quality. It is, however, merely a convenience, and in itself contains many imperfections. For example, all types of morphological abnormality are treated as though they are of equal significance in reducing the fertility of the semen, which is certainly not true. Moreover, although some allowance is made for the quality of motility by considering only progressing sperm, even among these degrees of directness of movement and of speed can be detected, though not easily measured. It was felt that the introduction of greater refinement into the computation would defeat its own end by rendering the calculation too complicated. Every patient is an individual problem. The 
fertility index establishes the grade of a man's fertility, but in deciding what steps should be taken to improve his chances of success all available data must be considered. Nevertheless the fertility index should prove useful in attempting to solve the difficult problem of male subfertility.

\section{Summary}

A method is described for calculating a fertility index from the observed density, morphology, and motility of sperm in human semen. Data are quoted establishing the validity of the index as a measure of semen quality. Its usefulness in assessing degrees of sub-fertility and as an indicator of response to therapy is discussed.
The author would like to thank Dr. Margare Jackson for allowing her clinical records to be used for checking the reproductive histories, and for hef interest and encouragement.

\section{REFBRENCES}

Falk, H. C., and Kaufman, S. A. (1950). Fertil. and Steril., 1, 489 Hammen, R. (1944). Studies on Impaired Fertility in Man, trans. by H. Andersen. Munksgaard, Copenhagen.

Harvey, C. (1951). Proc. Soc. Stud. Fertil., 3, 56.

and Jackson, M. H. (1945). Lancet, 2, 99, 134.

Hotchkiss, R. S. (1936). J. Amer. med. Ass., $107,1849$.

Lane-Roberts, C., Sharman, A., Walker, K., and Wiesner, B. P.1 (1939). Sterility and Impaired Fertility. Hamish Hamiltong London.

MacLeod, J. (1951). Fertil. and Steril., 2, 115.

Moench, G. L., and Holt, H. (1931). Amer. J. Obstet. Gynec., 220

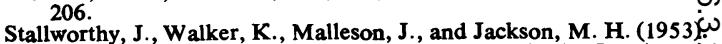
Problems of Fertility in General Practice. 2nd ed. London. N Weisman, A. I. (1941). Spermatozoa and Sterility. Hoeber, New 